\title{
Divide and compromise
}

DOI:

10.1016/j.mathsocsci.2017.04.004

\section{Document Version}

Submitted manuscript

Link to publication record in Manchester Research Explorer

\section{Citation for published version (APA):}

Nicolò, A., \& Velez, R. A. (2017). Divide and compromise. Mathematical social sciences, 90. https://doi.org/10.1016/j.mathsocsci.2017.04.004

\section{Published in:}

Mathematical social sciences

\section{Citing this paper}

Please note that where the full-text provided on Manchester Research Explorer is the Author Accepted Manuscript or Proof version this may differ from the final Published version. If citing, it is advised that you check and use the publisher's definitive version.

\section{General rights}

Copyright and moral rights for the publications made accessible in the Research Explorer are retained by the authors and/or other copyright owners and it is a condition of accessing publications that users recognise and abide by the legal requirements associated with these rights.

\section{Takedown policy}

If you believe that this document breaches copyright please refer to the University of Manchester's Takedown Procedures [http://man.ac.uk/04Y6Bo] or contact uml.scholarlycommunications@manchester.ac.uk providing relevant details, so we can investigate your claim.

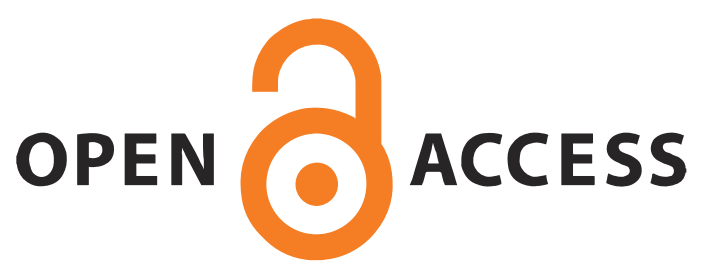




\title{
Divide and compromise
}

\author{
Antonio Nicolò ${ }^{\mathrm{a}}$ and Rodrigo A. Velez ${ }^{\mathrm{b} *}$ \\ ${ }^{a}$ Department of Economics, University of Padua, via del Santo 33, 35123 Padova, Italy and \\ School of Social Sciences, University of Manchester, Oxford Road, Manchester M13 9PL UK \\ ${ }^{b}$ Department of Economics, Texas A\&M University, College Station, TX 77843 USA
}

July 10, 2016

\begin{abstract}
We introduce a symmetrized version of the popular divide and choose mechanism for the allocation of a collectively owned indivisible good among two agents when monetary compensation is available. Our proposal retains the simplicity of divide and choose and corrects its ex-post asymmetry. When there is complete information, i.e., agents know each other well, it implements in subgame perfect equilibria a unique allocation that would be obtained by a balanced market. By correcting the expost asymmetry of divide and choose, our proposal may reduce welfare losses documented by laboratory studies for both divide and choose and auction-type mechanisms.
\end{abstract}

JEL classification: D63, C72.

Keywords: indivisible goods; no-envy; implementation in subgame perfect equilibria.

\section{Introduction}

When the final result is expected to be a compromise, it is often prudent to start from an extreme position.

John Maynard Keynes, The Economic Consequences of Peace

We consider the equitable allocation of a collectively owned object (indivisible good) when monetary compensation is available among two agents who

\footnotetext{
*All errors are our own. Nicolò antonio.nicolo@unipd.it and antonio.nicolo@manchester.ac.uk; Velez rvelezca@econmail.tamu.edu
} 
know each other well, as in the dissolution of a 50\%-50\% owned family business. ${ }^{1}$ Our main contribution is the introduction of a modified version of the popular divide and choose mechanism. Our mechanism resembles a natural sequential price negotiation in which both agents have the opportunity to make proposals and reach an agreement -see below for a precise description. Each subgame perfect equilibrium of our mechanism results in an equitable compromise independently of the order in which proposals are made. Thus, our proposal preserves the simplicity of the divide and choose mechanism and at the same time corrects its main flaw, i.e., that it is procedurally unfair. In laboratory experiments the divide and choose mechanism is superior to alternative auction-type mechanisms, but still underperforms in both equitability and efficiency due to its ex-post asymmetry (Guth et al., 1982; Brown and Velez, 2016). Thus, our proposal is not only normatively superior to divide and choose, but also may reduce efficiency losses in real life applications. ${ }^{2}$

The availability of equitable mechanisms is important in a market society. Economists have acknowledged the fundamental role of social trust for creating cooperation and have studied which factors are more relevant to determine the level of trust in a society. Ostrom (2000) points out that one of the key factors is the emergence of fair rules. ${ }^{3}$ Productive activities are often conducted by groups of individuals who join their effort to achieve common goals. Thus, economic growth is indeed fostered by economic and social institutions that favor welfare enhancing exchanges, trades, and business agreements.

Our aim then is to identify equitable mechanisms. Our first step is to identify equitable allocations. In order to do so one can find an intuitively equitable institution and then select the optimal allocations that in ideal conditions the institution would produce. In our case, this is achieved by a market in which each agent, thought to be a price taker, owns half of the aggregate income. These allocations, which we refer to as market allocations, capture much of our desiderata of equity. They are efficient (Svensson, 1983). Moreover, since agents have the same income, their budget sets are identical. Thus agents maximize in identical budget sets. Alternatively, in order to identify equitable allocations one can simply declare a desiderata of properties that an

\footnotetext{
${ }^{1}$ Symmetric two-party partnerships are the modal form of business cooperation. For instance, Hauswald and Hege (2006) find that the majority of US joint ventures recorded by the Thomson Financial Securities Data in the period 1985-2000 are 50\%-50\% agreements.

${ }^{2}$ It is an interesting question, beyond the scope of this paper, to experimentally evaluate the performance of our mechanism proposal.

3 "Fair rules of distribution help to build trusting relationships, since more individuals are willing to abide by these rules because they participated in their design and also because they meet shared concepts of fairness." (Ostrom, 2000, pag. 150).
} 
equitable allocation should have and then find the allocations that satisfy it. It turns out that requiring efficiency and that no agent prefer the allotment of the other, i.e., the celebrated no-envy (Foley, 1967; Varian, 1974), exactly conduces to the set of market allocations (Svensson, 1983). With this solid foundation we concentrate on the implementation of market allocations.

Our second step is to account for agents' incentives. It is well known that it is impossible to implement market allocations in dominant strategies (Alkan et al., 1991; Tadenuma and Thomson, 1995a). In view of this impossibility, one can construct games whose Nash equilibrium outcomes are market allocations. An intuitive way to do this is by means of a so called $\alpha$-auction: ask agents to bid for the object; then a highest bidder gets the object and transfers an $\alpha$-convex-combination between the winner and the loser bid (Cramton et al., 1987; Brown and Velez, 2016). ${ }^{4}$ Alternative simultaneous proposals abound. Unfortunately, it is well known that the performance of simultaneous move mechanisms is compromised by the presence of boundedly rational players (McKelvey and Palfrey, 1995). Indeed, the $\alpha$-auctions perform poorly in an experimental environment (Brown and Velez, 2016). This leads us to consider purely sequential mechanisms. The most popular alternative here is the so called divide and choose mechanism (Crawford and Heller, 1979; Crawford, 1980), which resembles the popular cake cutting procedure and implements in subgame perfect equilibria the "extremes" of the set of market outcomes. Here, an agent chosen at random proposes the transfer that the agent who gets the object gives the other agent. The second agent decides either to get the object and make the proposed transfer, or to give up the object and take the transfer. In any subgame perfect equilibrium, the proposer takes advantage of her role and extracts all possible "equity surplus" from the other agent. This ex-post asymmetry turns out to be problematic. In laboratory experiments subgame perfect proposals are received with a retaliation strategy from the chooser, who can induce a big loss for the proposer at a low cost to him by just choosing the inefficient outcome (Guth et al., 1982; Brown and Velez, 2016). This welfare loss is significant (Brown and Velez, 2016).

We are, hence, interested in solving both limitations of simultaneous move mechanisms and the procedurally unfair divide and choose. We proceed in two steps. First, we identify a market outcome that, away from the extremes chosen by divide and choose, is a compromise that balances the interests of both agents within the set of market allocations. One can argue that at each market allocation each agent perceives a bias towards herself. This bias can

\footnotetext{
${ }^{4}$ The online dispute resolution system http: / /www . fairoutcomes . com/ offers the intermediate price auction, i.e., $\alpha=\frac{1}{2}$, under the Fair Buy-Sell system.
} 
be measured for, say agent $i$, by the maximal amount of money that one can add to the consumption of the other agent without causing agent $i$ to prefer the other's allotment (Tadenuma and Thomson, 1995b). We select the market allocation at which the perceived biases of both agents are equal, which is essentially unique. We refer to it as the balanced market allocation. ${ }^{5}$ Then, we construct a simple sequential mechanism that implements in subgame perfect equilibria the balanced market allocation. ${ }^{6}$ Thus, our mechanism is procedurally fair. The equilibrium allocation is the same irrespectively of who the first mover in the game is.

Our mechanism works as follows. An agent, say agent $A$, announces to be either the buyer or the seller and proposes a price (the outcome of the game is independent of the identity of the first mover). Suppose agent $A$ announces to be the buyer and proposes price $p_{A}$. Agent $B$ can either, steal $A$ 's proposal and buy at $p_{A}$-which ends the game, or renegotiate and propose a price $p_{B}$. If agent $B$ renegotiates, agent $A$ can then either steal $B$ 's proposal and sell at $p_{B}$ -which ends the game, or compromise and buy at the average between $p_{A}$ and $p_{B}$. If agent $A$ announces to be the seller and proposes price $p_{A}$, the symmetric game unfolds.

An interesting feature of our mechanism is that its subgame perfect equilibria exhibits an intuitive feature of situations in which agents compromise. In equilibrium agents make proposals that one can characterize as extreme. However, their extreme proposals balance each other and an equitable compromise, the balance market outcome, is reached.

Our implementation result is obtained in a domain of preferences that contains, but is not restricted to, quasi-linear preferences. As long as agents' preferences are increasing in money, there will be an essentially unique balanced market allocation, which is implemented in subgame perfect equilibria by our mechanism. This level of generality, rarely found in implementation results, allows us to account for common phenomena as the complementarity of money and objects, or the natural asymmetry between making or receiving a money transfer under liquidity constraints (see Example 1).

\footnotetext{
${ }^{5}$ Our recommendations have the property that for a fixed preference profile, the welfare of each agent is an increasing function of the aggregate consumption of money (Velez, 2015a).

${ }^{6}$ Our approach is close in spirit to LiCalzi and Nicolò (2009) who identify a unique egalitarianequivalent allocation for a the land division problem and implement it in sub-game perfect equilibrium.
} 


\section{Related literature}

The equitable allocation of indivisible goods when monetary compensation is available has been the object of an extensive literature. Existence of market allocations has been established under very mild assumptions on preferences (Svensson, 1983; Maskin, 1987; Alkan et al., 1991; Velez, 2016). Even though the set of market allocations generically has a continuum of allocations, none of the popular axioms of solidarity, monotonicity, and consistency has produced any focal selection from the set. Due to this indeterminacy several authors have proposed selections from the set of market allocations based on intuitive criteria (e.g., Tadenuma and Thomson, 1995b; Aragones, 1995; Abdulkadiroğlu et al., 2004; Velez, 2011). Our balanced market allocation is indeed the allocation selected by the "equal-compensation solution" of Tadenuma and Thomson (1995b). Thus, a corollary of our result is that our mechanism implements in subgame perfect equilibria the equal-compensation solution in the two-agent case. The majority of studies that consider incentives issues in our environment have focused on simultaneous move mechanisms that fully implement the set of market allocations (Moulin, 1984; Tadenuma and Thomson, 1995a; Abdulkadiroğlu et al., 2004; Āzacis, 2008; Beviá, 2010; Velez, 2011; Andersson et al., 2014a,b; Velez, 2015b; Fujinaka and Wakayama, 2015) or mechanisms that hold no relation with market allocations (Brams and Kilgour, 2001). The closest paper to ours is Moulin (1984) whose conditional auction mechanism implements the market outcome in our environment when preferences are quasi-linear. In contrast with our simple mechanism, the conditional auction mechanism requires agents submit tridimensional simultaneous reports.

There is extensive literature studying the dissolution of a partnership in an incomplete information setting. The main interest is the design of ex-post efficient mechanisms that satisfy participation constraints. Surprisingly, in an independent, private-value setting, there are ex-post-efficient and interim-individually-rational, incentive-compatible mechanisms for a non-trivial set of ownership distributions that contains and is centered in the symmetric ownership case (Cramton et al., 1987). ${ }^{7}$ Only a few of the mechanisms that have been identified in this literature are of interest to us, for they usually depend on the distribution of agents' valuations. The most notable exceptions are the $\alpha$ auctions (Cramton et al., 1987) and the divide and choose mechanism (McAfee, 1992). Even though the divide and choose mechanism is not efficient under incomplete information, it has received great attention due to its simplicity and

\footnotetext{
${ }^{7}$ This basic result does not extend to more general information and types structure (see Moldovanu, 2002, for a survey).
} 
prevalence in practice (de Frutos and Kittsteiner, 2008). It turns out that if this mechanism is concatenated with an ascending price auction where agents bid for the right to choose, the mechanism becomes efficient. Interestingly, one can prove using similar fixed point arguments to those in our proofs, that under complete information, this concatenated mechanism has as unique subgame perfect equilibrium outcome the balanced market outcome. We favor our original price negotiation mechanism in order to implement the balanced market outcome, for it resembles a common price negotiation.

The divide and choose mechanism has been a focal point in the fair cake division literature (Brams and Taylor, 1996) and has been adapted to multiple environments (Crawford and Heller, 1979; Crawford, 1980; Moulin, 1981; Thomson, 2005). Closely related to our results, Nicolo and Yu (2008) propose a procedurally fair mechanism that obtains envy-free allocations in the cake division problem. The mechanism is a multi-step sequential game form in which each agent at each step receives a morsel of the cake that is the intersection of what she asks for herself and what the other agent concedes.

The paper proceeds as follows. In section 3 , we give preliminary notation and we introduce the problem we are dealing with. In section 4 we define the balanced market allocation we want to implement and describe our sequential mechanism to implement it. Section 5 concludes. An Appendix contains the statement and proof of a general form of our implementation result.

\section{The problem}

We consider two agents, $\{1,2\}$, who collectively and symmetrically own an object. Generic agents are $i$ and $j$. The object is to be assigned to one of the agents. They can compensate or be compensated with money. We assume that there is no limit in the amount of money that an agent can pay or receive. We normalize the initial endowments of money to zero. We denote the transfer from the agent who receives the object to the other agent by $x$. This transfer may be negative, meaning that the agent who does not receive the object compensates the agent who does -the object may represent a task for which the agents are collectively responsible. Our model is ordinal, i.e., our primitive is agent's preferences. For simplicity we introduce utility representation. Agent $i$ 's preferences are represented by a utility function that assigns $u_{i}(x)$ to receiving the object and transferring $x$ to the other agent. Each agent's utility of receiving transfer $x$ and no object is normalized to $x$. We assume that $u$ is onto, continuous, and strictly decreasing. With this we guarantee that the object has no infinite value in terms of money. Under these assumptions, there is 
a unique amount of money $x_{i}^{*}$ such that agent $i$ would be indifferent between receiving the object and transferring $x_{i}^{*}$ to agent $j$ or agent $j$ receiving the object and transferring $x_{i}^{*}$ to agent $i$, i.e., $x_{i}^{*}=u\left(x_{i}^{*}\right)$. We refer to $x_{i}^{*}$ as agent $i$ 's valuation for the object. Let $\underline{x}$ and $\bar{x}$ be the minimum and maximum of $x_{1}^{*}$ and $x_{2}^{*}$, respectively.

Our domain contains, but is not restricted to the domain of quasi-linear preferences. Formally, a preference is quasilinear if it admits a representation of the form $u_{i}(x)=\alpha_{i}-x$ for some $\alpha_{i} \in \mathbb{R}$.

The domain of quasi-linear preferences is popular in applications and is suitable for experimental work. The quasi-linear domain is narrow, however. For instance, it cannot capture the asymmetry of positive and negative transfers that is induced by liquidity constraints and other real life relevant phenomena. We illustrate with an example.

Example 1. Mark and Eduardo own a startup company together (50\% each). One year before they can get to an IPO they find irreconcilable differences and decide to terminate their partnership. The value of the company depends on which partner retains the company. Mark would be able to reach a market capitalization of $\$ 100$ million. Eduardo would reach $\$ 50$ million. Eduardo belongs to a wealthy family and has access to zero interest credit. Thus, Eduardo's utility of retaining the company and transferring $x$ (in millions) to Mark is $u_{E}(x)=$ $50-x$ and $x_{E}^{*}=25$ million. Mark, on the other hand, would have to pay the market effective annual rate, $r$, on any compensation that he gives Eduardo in order to retain the company. Thus, Mark's utility of retaining the company and transferring $x$ to Eduardo is $u_{M}(x)=100-(1+r) x$ and $x_{M}^{*}=\frac{100}{2+r}$.

We will come back to this example to illustrate our results and will assume throughout that $\underline{x}=x_{E}^{*}<x_{M}^{*}=\bar{x}$, i.e., annual effective interest rates are at most two hundred percent.

We are interested in the set of allocations that can be sustained as competitive equilibria in which each agent has an equal share of the aggregate income (Svensson, 1983). That is, there is a price $p$ for the object, each agent receives an income of $\frac{p}{2}$ and chooses between paying $p$ for the object or keeping income $\frac{p}{2}$, and market clears. We refer to these allocations as market allocations.

The set of market allocations can be described easily by means of the agents' values. Consider a price $p$. If $p \geq 2 \underline{x}$, the low valuation agent weakly prefers to free the object and get income $\frac{p}{2}$. If $p \leq 2 \bar{x}$, the high valuation agent weakly prefers to buy the object at price $p$. Thus, for each $p \in[2 \underline{x}, 2 \bar{x}]$ there is a competitive equilibrium in which the high valuation agent buys the object. For a price outside this interval, either both agents prefer to buy the object, or both prefer not to. Thus, the market clearing condition cannot be satisfied. Thus, 
the set of equilibrium prices is the interval $[2 \underline{x}, 2 \bar{x}]$ and the set of competitive equilibrium outcomes, i.e., market allocations, are those at which the high valuation agent receives the object and transfers an amount $x \in[\underline{x}, \bar{x}]$ to the low valuation agent. If both agents have equal valuations, there is essentially one market allocation at which any agent gets the company and transfers her valuation to the other agent.

Market allocations have attracted great interest in the study of fair allocation. Foley (1967) proposed them in order to achieve no-envy, i.e., the requirement that no agent prefer the consumption of any other agent to her own. In our environment, the set of market allocations coincides with the set of envyfree allocations (Svensson, 1983). Moreover, market allocations are also Pareto efficient.

It is impossible to make a strategy-proof selection from the set of market allocations (Alkan et al., 1991; van Damme, 1992; Tadenuma and Thomson, 1995a). ${ }^{8}$ This impossibility has been bypassed to some extent. A growing literature has investigated the non-cooperative equilibria of the direct revelation mechanisms that select market allocations for each preference profile. The common finding is that all these mechanisms are outcome equivalent. Their equilibria are exactly the set of market allocations for the true preferences (see Velez, 2015b, and references within). Since the set of market allocations depends only on agents' valuations, this result extends to the auction-like mechanisms that ask for agents' valuations and select a market allocation given those valuations. For instance, given reports, $\{\underline{x}, \bar{x}\}$, an agent with the highest valuation receives the object and transfers $\bar{x}$ to the other agent. This mechanism is known in the literature as "winners' bid auction." Even though the induced games of this auction may not have pure strategy Nash equilibria, they always have limit Nash equilibria, whose outcomes are exactly the set of market allocations: agents coordinate reporting valuations, one just above the other, in the interval $[\underline{x}, \bar{x}]$. Alternative outcome equivalent mechanisms are the "loser's bid auction" in which a high valuation agent receives the object and transfers $\underline{x}$ to the other agent, or more generally an $\alpha$-auction, in which the transfer is the convex combination $\alpha \underline{x}+(1-\alpha) \bar{x}$. The set of limit equilibria of all these mechanisms is the set of market allocations for the true preferences (Figure 1 ).

It is good news that the non-cooperative equilibrium outcomes from the manipulation of market mechanisms and $\alpha$-auctions are market allocations with respect to the true preferences. One may be interested in using a dif-

\footnotetext{
${ }^{8} \mathrm{~A}$ solution is strategy-proof if for each preference profile it is a dominant strategy to report her true preferences for each agent.
} 


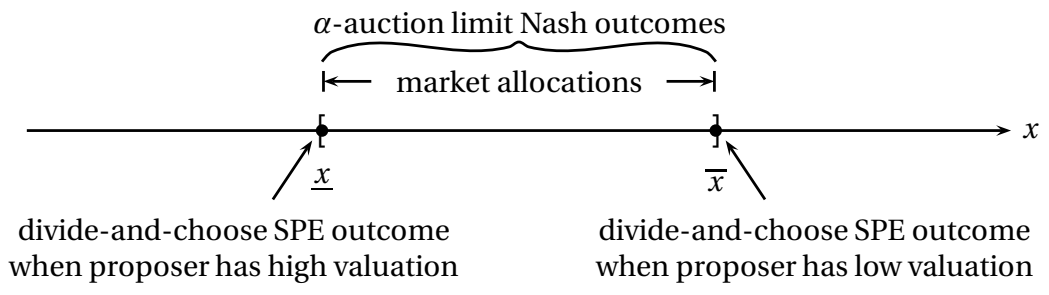

Figure 1: Geometric representation of market allocations and complete information prediction for equitable allocation mechanisms.

ferent mechanism, however. First, it may be desirable to have mechanisms that make more refined selections from the market allocations set. Second, all these mechanisms require agent's coordination and inherit the bounded rationality issues that have been identified by experimental economists for simultaneous games -more on this below. It turns out that as long as one uses a simultaneous-move mechanism, it is impossible to have equilibrium outcomes that are a proper subset of the market allocations (Tadenuma and Thomson, 1995a). Thus, in order to both attempt to achieve a finer selection of market allocations and improve the performance of the mechanism -at least in an experimental setting, it is necessary to consider sequential mechanisms.

Only a few sequential mechanisms that implement market allocations have been identified in the literature. The most prominent is the divide and choose mechanism: pick one agent at random to propose a transfer $x$ from the agent who receives the object to the other agent; then the other agent decides to get the object and transfer $x$ to the other agent, or get the transfer $x$. Instruction to use this mechanism are usually included, as a buy-sell clause-also known as a "Texas shootout," in partnership agreements (de Frutos and Kittsteiner, 2008). This mechanism has a unique subgame perfect Nash equilibrium, depending on who the proposer is. A high valuation proposer will offer a transfer $\underline{x}$ and the other agent would accept the transfer. A low valuation proposer will offer a transfer $\bar{x}$ and the other agent would get the object and transfer $\bar{x}$ to her (Figure 1).

Brown and Velez (2016) experimentally evaluated the performance of both winner's-bid auction and divide and choose mechanisms. Divide and choose obtained $81 \%$ market allocations and $85 \%$ efficient allocations. Winner's-bid auction obtained $47 \%$ market allocations and $73 \%$ efficient allocations. The differences are significant. It turns out that simultaneous nature of the winner'sbid auction induces a distortion that keeps agents away from Nash behavior. This distortion slightly improves over time, but does not improve to the level 
of divide and choose. Essentially, agents' actions are consistent with a quantal response equilibrium model: agents respond to the distribution of play of the other agents with a noisy best response that is induced by their inability to observe payoffs or by their bounded rationality; in equilibrium each player's distribution of play is the noisy best response to the distribution of play of the other agent.

Even though divide and choose mechanism significantly outperforms the winner's-bid auction, it still loses $15 \%$ of efficient allocations and $19 \%$ of competitive allocations with respect to the subgame Nash equilibrium prediction. This loss is caused by the asymmetry of the mechanism after the proposer is determined. In the subgame perfect equilibrium of the mechanism, the chooser is indifferent among the bundles offered by the proposer. Thus, when the proposer selects a proposal that is very close to the subgame perfect one, the chooser can, at almost no cost, punish the proposer by selecting the inefficient outcome. For instance, if a high valuation proposer, offers a transfer $\underline{x}+\delta$, the chooser would lose $2 \delta$ by selecting to get the object and doing the transfer. If $\delta$ is small, choosers indeed pay this cost and express their displeasure for the proposal.

This experimental evidence motivates our designing new sequential mechanisms that pick in unique subgame perfect Nash equilibrium a more central selection from the set of market allocations. Our restriction to sequential mechanisms allows us to aim for essentially single valued outcomes and avoid bounded rationality issues associates with simultaneous move mechanisms. By selecting more central allocations we intend to avoid the reciprocity issues that compromise the performance of divide and choose. We proceed in two steps. First, we borrow from the literature on normative economics and identify salient market allocations. Then we construct simple sequential mechanisms that select in unique subgame perfect equilibria this central allocation.

\section{A balanced market allocation and how to achieve it}

We are interested in finding a compromise between the interests of both agents among all market allocations. In order to do so we measure how biased each market allocation is and use this measure to select a central market allocation.

Recall that the set of market allocations is isomorphic to the interval $[\underline{x}, \bar{x}]$. At each market allocation a high valuation agent receives the object and transfers an amount in this interval to the other agent. From the point of view of the low valuation agent, the only unbiased market allocation is that in which she receives $\underline{x}$, because at this allocation both agents receive equal value allot- 
ments with respect to her own welfare index. Moreover, any other market allocation is biased towards her, for she finds her consumption preferable than that of the other agent. Curiously, exactly the same happens for the high valuation agent. From her point of view, $\bar{x}$ is only unbiased market allocation and all other market allocations are biased towards her. Thus, we cannot find an allocation that is perceived as unbiased by both agents. In general each market allocation will be perceived by both agents as being biased towards themselves. Our approach is then to measure these perceived biases in a comparable way and make them equal.

Tadenuma and Thomson (1995b) propose to measure how well an agent, say $i$, is treated in relation to agent $j$, at a market allocation $x$, by means of the maximal amount of money that can be added to the consumption of agent $j$ without causing agent $i$ to prefer $j$ 's allotment. For our high valuation agent, this bias, which we denote by $b_{h}(x)$, is the amount of money such that $u_{h}(x)=$ $x+b_{h}(x)$. For the low valuation agent, this bias, which we denote by $b_{l}(x)$, is the amount that would make indifferent the agent between being paid $x$ to give up the object or paying $x-b_{l}(x)$ for it, i.e., $u_{l}\left(x-b_{l}(x)\right)=x$. Since $b_{h}(\underline{x})-b_{l}(\underline{x}) \geq 0$, $b_{h}(\bar{x})-b_{l}(\bar{x}) \leq 0$, and this difference is a monotone function of $x$, a standard argument shows that there is a unique $\widehat{x}$ that makes the agents' perceived biases equal, i.e., $b_{h}(\widehat{x})=b_{l}(\widehat{x})$. We refer to this allocation as the balanced market allocation.

Example 1 (continuation). Recall that in our example, Mark is the high valuation agent and Eduardo the low valuation agent. Then, for a market allocation $x, 100-(1+r) x=x+b_{h}(x)$ and $50-\left(x-b_{l}(x)\right)=x$. Thus, $\widehat{x}=\frac{150}{4+r}$.

It is instructive to compare this balanced market allocation with the middle point of the interval of market allocations:

$$
\frac{\underline{x}+\bar{x}}{2}-\underline{x}=\frac{50-25 r}{4+2 r}<\frac{50-25 r}{4+r}=\widehat{x}-\underline{x} .
$$

Thus, the balanced market allocation is to the right of the median market allocation. Intuitively, this is so because each dollar that Eduardo gives up releases Mark from the burden of paying interest over that dollar. Thus, moving away from their respective worst market allocations, Mark's perceived bias increases quicker than Eduardo's.

Let us measure how sensitive our balanced market allocation is to the asymmetry in credit conditions for the agents by means of the percentage of the size of the set of market allocations that the credit constrained agent ends up paying in excess of the median market allocation, i.e.,

$$
\frac{\widehat{x}-\underline{x}}{\bar{x}-\underline{x}}-\frac{1}{2}=\frac{r}{2(4+r)} \text {. }
$$


For an annual effective interest rate of $8 \%$, the credit constrained agent will end up paying about $1 \%$ of the size of market allocations above the median market allocation.

We present a mechanism that implements the balanced market allocation in subgame perfect equilibria.

Alternating pricing game. A randomly selected agent, say agent $i$, proposes either to buy or sell the object and names a price. Suppose that $i$ proposes to but at $p_{i}$. Agent $j$ then has two options: (i) "steal agent $i$ 's deal" and buy at $p_{i}$; or (ii) renegotiate and propose a price $p_{j}$. If agent $j$ renegotiates, agent $i$ can either, steal agent $j$ 's deal and sell at $p_{j}$, or compromise and buy at $\frac{p_{i}+p_{j}}{2}$. If agent $i$ proposes to sell at $p_{i}$ instead, the symmetric game unfolds. That is, agent $j$ can steal agent $i$ 's deal and sell at $p_{i}$, or renegotiate and propose $p_{j}$ so agent $i$ can either steal agent $j$ 's deal and buy at $p_{j}$ or compromise and sell at the average price.

Theorem 1. The alternating pricing game implements in subgame perfect equilibrium the balanced market allocation. That is, each subgame perfect equilibrium outcome of the mechanism is the balanced market allocation and the balanced market allocation is a subgame perfect equilibrium outcome.

Example 1 (continuation). If Mark is asked to move first in the alternating pricing game (Figure 2), the game has a unique backward induction solution. In the equilibrium path Mark proposes to buy at a price $\widehat{P}_{M} \equiv 50 \frac{1+r}{4+r}$, Eduardo renegotiates the price and proposes $\widehat{P}_{E} \equiv 50 \frac{5-r}{4+r}$, and finally Mark buys at $\frac{\widehat{P}_{M}+\widehat{P}_{E}}{2}$ (see Appendix for the description of off equilibrium strategies). Symmetrically, if Eduardo is asked to move first, the game has a unique backward induction solution. In the equilibrium path Eduardo proposes to sell at $\widehat{P}_{E}$, Mark renegotiates the price and proposes $\widehat{P}_{M}$, and finally Eduardo sells at $\frac{\widehat{P}_{M}+\widehat{P}_{E}}{2}$.

We will discuss here the intuition behind the equilibrium and present a formal proof in the Appendix.

First we observe that both Mark and Eduardo reveal their roles as buyer and seller when they are given the opportunity to move first. This means that in the alternating pricing game it is not profitable to pretend to be a seller for a high valuation agent or to pretend to be a buyer for a low valuation agent. Consider for instance Mark. If he proposes to sell, he will actually end up buying at a price that is at least $\bar{x}$. It is not difficult to see why this is so. If Mark proposes to sell at a price higher than $\bar{x}$, Eduardo can actually exercise his "steal the deal" option and force Mark to buy at that price. If Mark proposes to sell at a price $P_{M}<\bar{x}$, things are not better for him. Recall that Mark is indifferent 


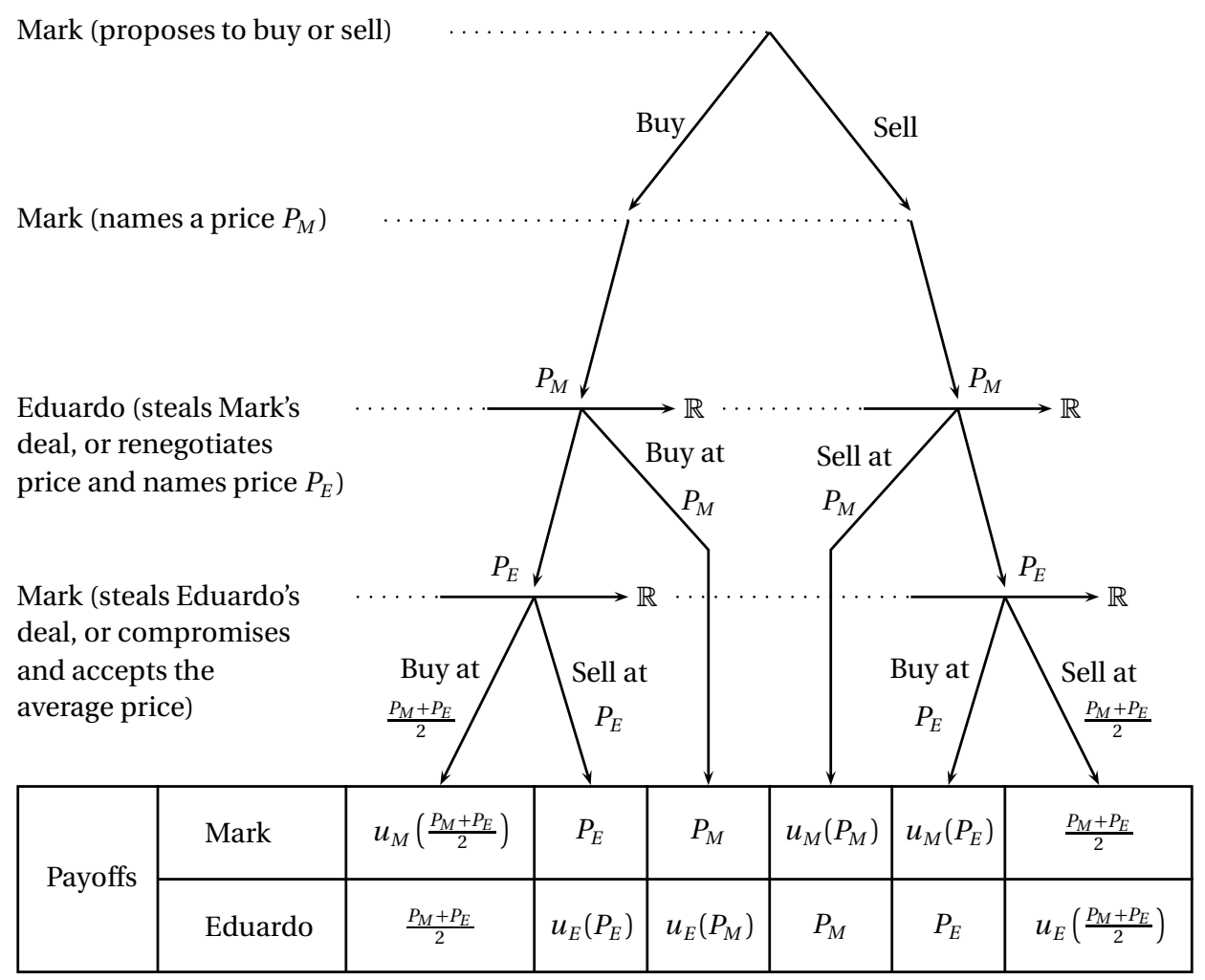

Figure 2: Extensive game for alternating pricing game mechanism when Mark is asked to move first.

from buying or selling at $\bar{x}$. Thus, Mark prefers to buy at $\bar{x}$ than selling at $P_{M}$, i.e., $u_{M}(\bar{x})>P_{M}$. If Eduardo renegotiates and proposes a price $P_{E}=\bar{x}+\delta$, Mark will actually buy at that price when $\delta>0$ is small compared with $\bar{x}-P_{M}$. We will see next that by proposing to be a buyer, Mark can actually buy at a price lower than $\bar{x}$. In this way our mechanism gives the incentives to the first mover to announce his real role in the transaction.

Now, imagine that Mark proposes to buy at a price $P_{M} \equiv \underline{x}$. Eduardo can then wither buy at $\underline{x}$ or propose a price $P_{E}$. Eduardo knows that contingent on price $P_{E}$, Mark will choose his best between selling at $P_{E}$ and buying at $\frac{\underline{x}+P_{E}}{2}$. Thus, Eduardo's optimal response is $P_{E}$ such that $u_{M}\left(\frac{P_{M}+P_{E}}{2}\right)=P_{E}$. If Eduardo proposes $\bar{x}$, Mark strictly prefers to buy at $\frac{\underline{x}+\bar{x}}{2}$. Thus, Eduardo's optimal proposal, which we denote $P_{E}(\underline{x})$, is greater than $\bar{x}$. Since Mark is indifferent between buying and selling at $\bar{x}$, then the average price for the optimal response for Eduardo, i.e., $\frac{\bar{x}+P_{E}(\underline{\underline{x}})}{2}$ is less than $\bar{x}$. Since Eduardo is indifferent between 
buying and selling at $\underline{x}$, he prefers Mark buying at $\frac{\bar{x}+P_{E}(\underline{x})}{2}>\underline{x}$, than he buying at $\underline{x}$ (steal the deal option) or at $P_{E}(\underline{x})>\bar{x}$. Thus, by proposing to buy at $\underline{x}$, Mark can actually buy at a price that is less than $\bar{x}$, his best outcome if he would pretend to be a seller.

Observe that if Mark proposes to buy at $\bar{x}$, Eduardo strictly prefers to sell at $\frac{\left.\bar{x}+P_{E} \underline{\underline{x}}\right)}{2}>\underline{x}$ than exercising his steal the deal option and buying himself at $\underline{x}$. Of course Eduardo will not buy at $P_{E}(\underline{x})>\bar{x}$. Thus, Mark still has room for obtaining a better deal buy offering to buy at a price lower than $\underline{x}$. The lowest price that Mark can achieve makes Eduardo indifferent between buying at $P_{M}$ and selling at $\frac{P_{M}+P_{E}\left(P_{M}\right)}{2}$, i.e.,

$$
u_{E}\left(P_{M}\right)=\frac{P_{M}+P_{E}\left(P_{M}\right)}{2} .
$$

Since Eduardo will extract all that he can from Mark, then Mark will be indifferent between buying at $\frac{P_{M}+P_{E}\left(P_{M}\right)}{2}$ and selling at $P_{E}\left(P_{M}\right)$, i.e.,

$$
u_{M}\left(\frac{P_{M}+P_{E}\left(P_{M}\right)}{2}\right)=P_{E}\left(P_{M}\right)
$$

Equations (1) and (2) have a unique solution $P_{M}=\widehat{P}_{M}$ and $P_{E}\left(\widehat{P}_{M}\right)=\widehat{P}_{E}$ as defined in our description of the equilibrium path actions. Thus, if we denote by $\Delta \equiv \widehat{P}_{E}-\widehat{P}_{M}$

$$
u_{E}\left(\frac{\widehat{P}_{M}+\widehat{P}_{E}}{2}-\frac{1}{2} \Delta\right)=\frac{\widehat{P}_{M}+\widehat{P}_{E}}{2} \text { and } u_{M}\left(\frac{\widehat{P}_{M}+\widehat{P}_{E}}{2}\right)=\frac{\widehat{P}_{M}+\widehat{P}_{E}}{2}+\frac{1}{2} \Delta .
$$

Thus,

$$
b_{M}\left(\frac{\widehat{P}_{M}+\widehat{P}_{E}}{2}\right)=b_{E}\left(\frac{\widehat{P}_{M}+\widehat{P}_{E}}{2}\right)=\frac{1}{2} \Delta
$$

and

$$
\widehat{x}=\frac{\widehat{P}_{M}+\widehat{P}_{E}}{2} .
$$

Summarizing, in equilibrium there is indeed a price negotiation. First, Mark lowballs Eduardo and offers to buy for an unrealistic price $\widehat{P}_{M}<\underline{x}$. Then, Eduardo renegotiates the price and proposes an unrealistically high price $\widehat{P}_{E}>\bar{x}$. These two unrealistic proposals offset each other: their average is the balanced market transfer. Finally, Mark compromises and buys at the average price, leading to the balanced market allocation.

For instance if $r$ is ten percent, the lowest competitive transfer $\underline{x}$ is $\$ 25$ million and the highest $\bar{x}$ is $\$ 47,619,048$. If Mark moves first, he proposes to buy 
at $\$ 13,414,634$, an unrealistic price knowing that Eduardo would prefer to buy at that price rather than selling. Eduardo can renegotiate, however. Indeed, Eduardo proposes a price of $\$ 59,756,098$. This price would be unrealistic too, for Mark prefers to sell at this price rather than buying. The average of these prices, i.e., $\$ 36,585,366$ is the balanced competitive transfer. Mark finally buys at this price.

The case when Eduardo moves first is symmetric.

\section{Concluding remarks}

Many experts of real life negotiations point out that the secret of a successful mediation is to help parties in reaching a fair compromise. We design a mechanism that in a two-agent division problem helps parties to share the surplus in an equitable way. The basic intuition of why our mechanism succeeds in reaching a fair compromise is that each party is refrained from making unreasonable requests by the threat that the other party could shift her role (from buyer to seller and viceversa). Since both parties have the opportunity to shift her role, then our mechanism is also procedural fair and implements a balanced market allocation.

\section{Appendix: a general result}

One can describe the balanced market allocation as that in which the aggregate bias in the economy is shared equally by both agents. An arbitrator may have different social objectives than equalizing biases among agents, however. There may be verifiable characteristics of the agents that grant different treatment of the agents. For instance, the government may be interested in favoring minorities or small business owners.

Without giving up the market allocations, the arbitrator can favor an agent by selecting an allocation that ensures a given percentage of the aggregate bias to a certain agent. Given $\rho \in[0,1]$ and agent $i$, Tadenuma and Thomson (1995b) propose to select the allocation that gives a proportion $\rho$ of the aggregate bias to this agent. One can easily show that for $i \in N$, there is a unique $x \in[\underline{x}, \bar{x}]$ such that

$$
\frac{b_{i}(x)}{b_{i}(x)+b_{j}(x)}=\rho \text {. }
$$

We denote this market allocation by $\widehat{x}_{\rho}^{i}$. Observe that the balance market allocation is indeed $\widehat{x}_{\frac{1}{2}}^{i}$ independently of the identity of $i \in N$. Moreover, for each 
$\rho, \widehat{x}_{\rho}^{i}=\widehat{x}_{1-\rho}^{j}$.

Our mechanism can be modified so it implements $\widehat{x}_{\rho}^{i}$ in subgame perfect equilibria. It is of course more likely that the reciprocity issues that affect the performance of the divide and choose mechanism, affect less the mechanisms with a more central target, i.e., a $\rho$ closer to $\frac{1}{2}$.

$(\boldsymbol{i}, \boldsymbol{\rho})$-alternating pricing game. Agent $i$, proposes either to buy or sell the object and names a price. Suppose that $i$ proposes to buy at $p_{i}$. Agent $j$ then has two options: (i) "steal agent $i$ 's deal" and buy at $p_{i}$; or (ii) renegotiate and propose a price $p_{j}$. If agent $j$ renegotiates, agent $i$ can either, steal agent $j$ 's deal and sell at $p_{j}$, or compromise and buy at $\rho p_{i}+(1-\rho) p_{j}$. If agent $i$ proposes to sell at $p_{i}$ instead, the symmetric game unfolds. That is, agent $j$ can steal agent $i$ 's deal and sell at $p_{i}$, or renegotiate and propose $p_{j}$ so agent $i$ can either steal agent $j$ 's deal and buy at $p_{j}$ or compromise and sell at $\rho p_{i}+(1-\rho) p_{j}$.

Theorem 2. The $(i, \rho)$-alternating pricing game implements in subgame perfect equilibrium $\widehat{x}_{\rho}^{i}$. That is, each subgame perfect equilibrium outcome of the mechanism is $\widehat{x}_{\rho}^{i}$, and $\widehat{x}_{\rho}^{i}$ is a subgame perfect equilibrium outcome.

Proof. In order to avoid trivialities suppose that $\rho \in(0,1)$ and $\underline{x}<\bar{x}$. Suppose first that agent $i$ is a high valuation agent. We solve the game by backward induction.

First, observe that since $u_{i}$ is continuous, onto, and decreasing, for each $P_{i} \in \mathbb{R}$, there is a unique $q\left(P_{i}\right) \in \mathbb{R}$ such that $u_{i}\left(\rho P_{i}+(1-\rho) q\left(P_{i}\right)\right)=q\left(P_{i}\right)$. Moreover, $q\left(P_{i}\right)$ is decreasing and onto. Since $u_{i}$ is decreasing, $\rho P_{i}+(1-\rho) q\left(P_{i}\right)$ is an increasing function of $P_{i}$. We claim that $q$ is a continuos function. Let $\left\{P_{i}^{t}\right\}_{t=1}^{\infty}$ be a convergent sequence and $P_{i} \equiv \lim _{t \rightarrow \infty} P_{i}^{t}$. Since the sequence is convergent, then it is bounded. Since $q$ is monotone, then the sequence $\left\{q\left(P_{i}^{t}\right)\right\}_{t=1}^{\infty}$ is also bounded. Consider an arbitrary subsequence, which we denote by $\left\{\tilde{P}_{i}^{t}\right\}_{t=1}^{\infty}$, such that $\left\{q\left(\tilde{P}_{i}^{t}\right)\right\}_{t=1}^{\infty}$ is convergent. Let $\tilde{q} \equiv \lim _{t \rightarrow \infty} q\left(\tilde{P}_{i}^{t}\right)$. Since $u_{i}$ is continuous, then $u_{i}\left(\rho P_{i}+(1-\rho) \tilde{q}\right)=\tilde{q}$. Thus, $\tilde{q}=q\left(P_{i}\right)$. Since $\left\{q\left(P_{i}^{t}\right)\right\}_{t=1}^{\infty}$ is bounded and each of its convergent subsequences converges to $q\left(P_{i}\right)$, then $\left\{q\left(P_{i}^{t}\right)\right\}_{t=1}^{\infty}$ is convergent and its limit is $q\left(P_{i}\right)$. Thus, $q$ is continuous. Thus, $\rho P_{i}+(1-\rho) q\left(P_{i}\right)$ is also onto.

Since $u_{j}$ is a continuous, onto, and decreasing function and $\rho P_{i}+(1-\rho) q\left(P_{i}\right)$ is a continuous, onto, and increasing function of $P_{i}$, then there is a unique $P_{i}$, which we denote by $\widehat{P}_{i}$, such that $u_{j}\left(\widehat{P}_{i}\right)=\rho \widehat{P}_{i}+(1-\rho) q\left(\widehat{P}_{i}\right)$. Since $q(\bar{x})=\bar{x}$, then $q(\underline{x})>\bar{x}$. Thus, $u_{j}(\underline{x})<\rho \underline{x}+(1-\rho) q(\underline{x})$. Thus, $\widehat{P}_{i}<\underline{x}$ and $q\left(\widehat{P}_{i}\right)>\bar{x}$.

Suppose that agent $i$ has proposed to buy at price $P_{i}$ and agent $j$ renegotiated and proposed price $P_{j}$. Then, agent $i$ buys at $\rho P_{i}+(1-\rho) P_{j}$, when $u_{i}\left(\rho P_{i}+(1-\rho) P_{j}\right)>P_{J}$ and sells at $P_{j}$ when $u_{i}\left(\rho P_{i}+(1-\rho) P_{j}\right)<P_{j}$. Suppose 
now that agent $i$ proposed to buy at $P_{i}$. Then agent $j$ 's utility of the different actions is: $u_{j}\left(P_{i}\right)$ if buying at $P_{i} ; u_{j}\left(P_{j}\right)$ if renegotiating and proposing $P_{j}>q\left(P_{i}\right)$; and $\rho P_{i}+(1-\rho) q\left(P_{i}\right)$ if renegotiating and proposing $P_{j}<q\left(P_{i}\right)$. If $P_{i}>\widehat{P}_{i}$, then $\rho P_{i}+(1-\rho) q\left(P_{i}\right)>u_{j}\left(P_{i}\right)$. Thus, agent $j$ will play a best response whenever can achieve a utility level of $\max \left\{u_{j}\left(q\left(P_{i}\right)\right), \rho P_{i}+(1-\rho) q\left(P_{i}\right)\right\}$. Thus, in a SPE agent $i$ must choose the best for agent $j$ when indifferent between $P_{i}>\widehat{P}_{i}$ and agent $j$ renegotiates and proposes $P_{j}=q\left(P_{i}\right)$. Let $p$ be such that $q(p)=\underline{x}$. Since $q(\bar{x})=\bar{x}$, then $p>\bar{x}$. Thus, $u_{j}(\underline{x})=\underline{x}<\rho p+(1-\rho) \underline{x}$. Thus, there is a unique $P_{i}^{*}>\widehat{P}_{i}$ such that, $u_{j}\left(q\left(P_{i}^{*}\right)\right), \rho P_{i}^{*}+(1-\rho) q\left(P_{i}^{*}\right)$. Moreover, $q\left(P_{i}^{*}\right)<\underline{x}$. Thus, in a SPE, if agent $i$ proposes to buy at $P_{i}>\widehat{P}_{i}$, her utility is:

$$
\left\{\begin{array}{rll}
u_{i}\left(\rho P_{i}+(1-\rho) q\left(P_{i}\right)\right) & \text { if } & \widehat{P}_{i}<P_{i}<P_{i}^{*}, \\
q\left(P_{i}\right) & \text { if } & P_{i}^{*}<P_{i} .
\end{array}\right.
$$

If agent $i$ proposes to buy at $P_{i}^{*}$, her utility is at most the maximum between $q\left(P_{i}\right)$ and $u_{i}\left(\rho P_{i}+(1-\rho) q\left(P_{i}\right)\right)$. Now, if $P_{i}<\widehat{P}_{i}$, then $u_{j}\left(P_{i}\right)>\rho P_{i}+(1-\rho) q\left(P_{i}\right)>$ $u_{j}(\bar{x})>u_{j}\left(q\left(P_{i}\right)\right)$. Thus, if agent $i$ proposes to buy at $P_{i}<\widehat{P}_{i}$, in a subgame perfect equilibrium agent $j$ buys at $P_{i}$. Thus in a SPE agent $i$ can guarantee a utility arbitrarily close to $u_{i}\left(\rho \widehat{P}_{i}+(1-\rho) q\left(\widehat{P}_{i}\right)\right)$. Moreover, agent $i$ 's utility of proposing to buy is bounded above by $u_{i}\left(\rho \widehat{P}_{i}+(1-\rho) q\left(\widehat{P}_{i}\right)\right)$.

Now, if agent $i$ proposes to sell at $P_{i}$ and agent $j$ renegotiates and proposes $P_{j}$, in a SPE, agent $i$ buys at $P_{j}$ if $u_{i}\left(P_{j}\right)>\rho P_{i}+(1-\rho) P_{j}$ and sells at $\rho P_{i}+(1-\rho) P_{j}$ if $u_{i}\left(P_{j}\right)<\rho P_{i}+(1-\rho) P_{j}$. One can show (see above) that there is a unique $r\left(P_{i}\right)$ such that $u_{i}\left(P_{j}\right)=\rho P_{i}+(1-\rho) P_{j}$, that $r\left(P_{i}\right)$ is decreasing in $P_{i}$, and that $\rho P_{i}+(1-\rho) r\left(P_{i}\right)$ is increasing in $P_{i}$. Clearly, $r(\bar{x})=\bar{x}$. Thus, in a SPE if agent $i$ proposes to sell at $P_{i}$ and agent $j$ renegotiates and proposes $P_{j}$, agent $j$ 's utility is

$$
\left\{\begin{array}{rll}
P_{j} & \text { if } & P_{j}<r\left(P_{i}\right) \\
u_{j}\left(\rho P_{i}+(1-\rho) P_{j}\right) & \text { if } & P_{j}>r\left(P_{i}\right)
\end{array}\right.
$$

Suppose that agent $i$ proposes to sell at $P_{i}>\bar{x}$. Since $r\left(P_{i}\right)<\bar{x}<\rho P_{i}+(1-$ $\rho) r\left(P_{i}\right)$,

$$
P_{i}>\max \left\{u_{j}(\underline{x}), \bar{x}\right\} \geq \max \left\{u_{j}\left(\rho P_{i}+(1-\rho) r\left(P_{i}\right)\right), r\left(P_{i}\right),\right\} .
$$

Thus, in a SPE, if agent $i$ proposes to sell at $P_{i}>\bar{x}$, agent $j$ will sell at $P_{i}$ and agent $i$ 's utility will be $u_{i}\left(P_{i}\right)<u_{i}(\bar{x})$. Suppose now that agent $i$ proposes to sell at $P_{i}<\bar{x}$. Thus, $P_{j}<\bar{x}<r\left(P_{i}\right)$. Thus, in a SPE, if agent $i$ proposes to sell at $P_{i}<\bar{x}$, agent $j$ will necessarily renegotiate and propose $r\left(P_{i}\right)$ and agent $i$ will break the tie between buying at $r\left(P_{i}\right)$ and selling at $\rho P_{i}+(1-\rho) r\left(P_{i}\right)$ in favor of agent $j$. Thus, in a SPE, if agent $i$ proposes to sell at $P_{i}<\bar{x}$, her utility will be at 
most $u_{i}\left(r\left(P_{i}\right)\right)<u_{i}(\bar{x})$. In a SPE, if agent $i$ proposes to sell at $\bar{x}$, either agent $j$ sells at $\bar{x}$, or renegotiates and proposes $\bar{x}$ and agent $i$ buys at $\bar{x}$. In any case, agent $i$ 's utility is $u_{i}(x)$.

Thus, in a SPE, the unique best response of agent $i$ is to propose to buy at $\widehat{P}_{i}$, then agent $j$ renegotiates and proposes $\widehat{P}_{j} \equiv q\left(\widehat{P}_{i}\right)$, and finally, agent $i$ buys at $\rho \widehat{P}_{i}+(1-\rho) \widehat{P}_{j}$.

Let $\Delta \equiv \widehat{P}_{j}-\widehat{P}_{i}>0$ and $z \equiv \rho \widehat{P}_{i}+(1-\rho) \widehat{P}_{j}$. Recall that $u_{j}\left(\widehat{P}_{i}\right)=\rho \widehat{P}_{i}+(1-\rho) \widehat{P}_{j}$ and $u_{i}\left(\rho \widehat{P}_{i}+(1-\rho) \widehat{P}_{j}\right)=\widehat{P}_{j}$. Thus,

$$
u_{j}(z-(1-\rho) \Delta)=z \text { and } u_{i}(z)=z+\rho \Delta .
$$

Thus, $b_{i}(z)=\rho \Delta, b_{j}(z)=(1-\rho) \Delta$, and $z=\widehat{x}_{\rho}^{i}$.

If agent $i$ is a low valuation agent, one can see that backward induction singles out a unique equilibrium path play: agent $i$ proposes to sell at $\widehat{P}_{i}>$ $\bar{x}$, agent $j$ renegotiates and proposes price $\widehat{P}_{j}<\underline{x}$. These prices are uniquely defined by the system:

$$
u_{j}\left(\rho \widehat{P}_{i}+(1-\rho) \widehat{P}_{j}\right)=\widehat{P}_{i} \text { and } u_{i}\left(\widehat{P}_{j}\right)=\rho \widehat{P}_{i}+(1-\rho) \widehat{P}_{j} .
$$

Then, agent $i$ sells at $z \equiv \rho \widehat{P}_{i}+(1-\rho) \widehat{P}_{j}$. Let $\Delta \equiv \widehat{P}_{i}-\widehat{P}_{j}$. Then, $u_{j}(z)=z+(1-$ $\rho) \Delta$ and $u_{i}(z-\rho \Delta)=z$. Thus, $z=\widehat{x}_{\rho}^{i}$.

\section{References}

Abdulkadiroğlu, A., Sönmez, T., Ünver, U., 2004. Room assignment-rent division: A market approach. Soc. Choice Welfare 22 (3), 515-538.

URL http://dx.doi .org/10.1007/s00355-003-0231-0

Alkan, A., Demange, G., Gale, D., 1991. Fair allocation of indivisible goods and criteria of justice. Econometrica 59 (4), 1023-1039.

URL http://www. jstor .org/stable/2938172

Andersson, T., Ehlers, L., Svensson, L.-G., 2014a. Budget-balance, fairness and minimal manipulability. Theoretical Econ. 9 (3), 753-777.

URLhttp://econtheory.org/ojs/index.php/te/article/view/20140753/0

Andersson, T., Ehlers, L., Svensson, L.-G., 2014b. Least manipulable envy-free rules in economies with indivisibilities. Math. Soc. Sc. 69, 43-49.

URL http://dx.doi.org/10.1016/j.mathsocsci.2014.01.006

Aragones, E., 1995. A derivation of the money rawlsian solution. Soc. Choice Welfare 12 (3), 267-276.

URL http://dx.doi.org/10.1007/BF00179981 
Āzacis, H., 2008. Double implementation in a market for indivisible goods with a price constraint. Games Econ. Behav. 62 (1), 140-154.

URL http://dx.doi.org/10.1016/j.geb. 2007.01.011

Beviá, C., 2010. Manipulation games in economies with indivisible goods. Int. J. Game Theory 39 (1-2), 209-222.

URL http://dx.doi.org/10.1007/s00182-009-0200-7

Brams, S., Taylor, A., 1996. Fair Division : From Cake-Cutting to Dispute Resolution. Cambridge University Press.

Brams, S. J., Kilgour, D. M., 2001. Competitive fair division. J. Polit. Economy 109 (2), 418-443.

URL http://www.jstor .org/stable/10.1086/319550

Brown, A. L., Velez, R. A., 2016. The costs and benefits of symmetry in commonownership allocation problems. Games Econ. Behav. 96, 115-131. URLhttp://www.sciencedirect.com/science/article/pii/S0899825616000129

Cramton, P., Gibbons, R., Klemperer, P., 1987. Dissolving a partnership efficiently. Econometrica 55 (3), 615-632.

URL http://www.jstor.org/stable/1913602

Crawford, V., 1980. Maximin behavior and efficient allocations. Econ. Letters 6, 211-215.

URL http: //dx.doi.org/10.1016/0165-1765(80)90018-X

Crawford, V. P., Heller, W. P., 1979. Fair division with indivisible commodities. Journal of Economic Theory 21 (1), 10-27. URL http://dx.doi.org/10.1016/0022-0531(79)90003-6

de Frutos, M.-A., Kittsteiner, T., 2008. Efficient partnership dissolution under buy-sell clauses. The RAND Journal of Economics 39 (1), 184-198. URL http://dx.doi.org/10.1111/j.1756-2171.2008.00009.x

Foley, D., 1967. Resource allocation and the public sector. Yale Economic Essays 7, 45-98.

Fujinaka, Y., Wakayama, T., 2015. Maximal manipulation of envy-free solutions in economies with indivisible goods and money. J. Econ. Theory 158, Part A, 165-185.

URL http://dx.doi.org/10.1016/j · jet.2015.03.014 
Guth, W., Schmittberger, R., Schwarze, B., 1982. An experimental analysis of ultimatum bargaining. Journal of Economic Behavior \& Organization 3 (4), $367-388$.

URL http: //dx.doi.org/10.1016/0167-2681(82)90011-7

Hauswald, R., Hege, U., 2006. Ownership and control in joint ventures, mimeo.

LiCalzi, M., Nicolò, A., 2009. Efficient egalitarian equivalent allocations over a single good. Econ. Theory 40 (1), 27-45.

URL http://dx.doi.org/10.1007/s00199-008-0361-9

Maskin, E., 1987. On the fair allocation of indivisible goods. In: Feiwel, G. (Ed.), Arrow and the Foundations of the Theory of Economic Policy. NY Univ. Press, pp. 341-349.

McAfee, P. R., 1992. Amicable divorce: Dissolving a partnership with simple mechanisms. Journal of Economic Theory 56 (2), 266-293. URL http: //dx.doi.org/10.1016/0022-0531(92)90083-T

McKelvey, R. D., Palfrey, T. R., 1995. Quantal response equilibria for normal form games. Games and Economic Behavior 10 (1), 6-38. URL http://dx.doi.org/10.1006/game.1995.1023

Moldovanu, B., 2002. How to dissolve a partnership. Journal of Institutional and Theoretical Economics (JITE) / Zeitschrift für die gesamte Staatswissenschaft 158 (1), pp. 66-80.

URL http://www . jstor .org/stable/40753054

Moulin, H., 1981. Implementing just and efficient decision-making. Journal of Public Economics 16 (2), 193 - 213.

URL http://dx.doi.org/10.1016/0047-2727(81)90024-4

Moulin, H., 1984. The conditional auction mechanism for sharing a surplus. Rev. Econ. Stud. 51 (1), 157-170.

URL http://www. jstor .org/stable/2297711

Nicolo, A., Yu, Y., 2008. Strategic divide and choose. Games Econ. Behav. 64 (1), $268-289$.

URL http://dx.doi.org/10.1016/j.geb.2008.01.006

Ostrom, E., 2000. Collective action and the evolution of social norms. The Journal of Economic Perspectives 14 (3), 137-158.

URL http: //www. jstor .org/stable/2646923 
Svensson, L.-G., 1983. Large indivisibles: an analysis with respect to price equilibrium and fairness. Econometrica 51 (4), 939-954.

URL http: //www . jstor .org/stable/1912044

Tadenuma, K., Thomson, W., 1995a. Games of fair division. Games Econ. Behav. 9 (2), 191-204.

URL http://dx.doi.org/10.1006/game.1995.1015

Tadenuma, K., Thomson, W., 1995b. Refinements of the no-envy solution in economies with indivisible goods. Theory and Decision 39 (2), 189-206.

URL http://dx.doi.org/10.1007/BF01078984

Thomson, W., 2005. Divide-and-permute. Games Econ. Behav. 52 (1), 186 - 200. URL http://dx.doi.org/10.1016/j.geb.2004.06.009

van Damme, E., 1992. Fair division under asymmetric information. In: Selten, R. (Ed.), Essays in Honor of John C. Harsanyi. Springer, Berlin - Heidelberg, pp. 121-144.

Varian, H. R., 1974. Equity, envy, and efficiency. J. Econ. Theory 9 (1), 63 - 91. URL http://dx.doi.org/10.1016/0022-0531(74)90075-1

Velez, R., 2011. Are incentives against economic justice? J. Econ. Theory 146 (1), 326-345.

URL http://dx.doi.org/10.1016/j.jet.2010.10.005

Velez, R. A., 2015a. Sharing an increase of the rent fairly, mimeo, Texas A\&M University.

URL http://respec.tamu .edu/velezsharingrent.pdf

Velez, R. A., 2015b. Sincere and sophisticated players in an equal-income market. J. Econ. Theory 157, 1114-1129.

URL http://dx.doi.org/10.1016/j.jet.2015.03.006

Velez, R. A., 2016. Fairness and externalities. Theoretical Econ. 11, 381-410. URL http://dx.doi.org/10.3982/TE1651 